\title{
Hankering after past glory
}

\section{Berlin}

WITH the approaching reunification of Germany, Berlin is hoping to assert itself again as one of world's great centres of academic excellence, on a par with Boston or Berkeley. But there are many obstacles in the way and it is by no means clear how and when they will be overcome.

Until the Nazi takeover in 1933, Berlin could claim to be the preeminent scientific city in Europe, thanks to the benevolent policies of Kaiser Wilhelm II and the vigorous efforts of researchers such as Max Planck. Now the challenge is to recreate that strength by integrating the institutes created after the Second World War on the two sides of the Wall.

The reunified Berlin will contain three large universities, more than 20 West German research centres and approximately half of the nearly one hundred scientific institutions in East Germany. "At least quantitatively, we are on a par with the top cities of science in Europe and even in the United States", says Werner Väth, vice-president of the Free University of Berlin.

For very different reasons, science in both West and East Berlin profited from the 40 -year division resulting from the Cold War. West Germany jammed the city with institutions of science and culture to keep it parliamentary democracy in Germany.

vital and attractive despite its location in / recommendations.

the middle of East Germany and the departure of most of its heavy industry in the 1950s and 1960s. And East Germany made East Berlin a showplace of scientific and technical prowess - to the detriment of the hinterlands.

The city has other advantages, principally its location. Once perched on the periphery of a divided Europe, Berlin now stands at the threshold of a revitalized Central and Eastern Europe. As in its glory days from 1880 to 1930 , Berlin could once again become a focus of East-West exchange, especially if it maintains the contacts with Moscow established by East Germany.

But renewal will be arduous. Supporters of Berlin's renewal, led by West Berlin Science Senator Barbara RiedmüllerSeel, must negotiate a minefield before they reach their immediate goal of a plan for the integration and unification of science in the city.

The first task is to find out exactly what East German science has to offer. Despite the disappearence of the Berlin Wall, research in East Berlin is still an unknown Germany. quantity. Over the objections of those who first wanted to cut off support to East German researchers after reunification (on the grounds that many researchers were compromised by being members of the Communist Party), the West German science advisory council Wissenschaftsrat will carry out a project-by-project evaluation of the grossly overstaffed East German Academy of Sciences, where the Communist regime concentrated its best researchers and equipment (see Nature 346, 209; 1990). Wissenschaftsrat will say whether institutes should be absorbed by universities or industry or be shut down. Politicians have promised to abide by the fields in the humanities and social sciences, says Riedmüller-Seel, a policy necessary to meet the influx of East German students. Western students are not expected to enter the Humboldt University for several years, after the quality and image of the faculty (and its members' pay, now one-third of that in the West) has improved.

Perhaps the biggest problem that Riedmüller-Seel will have to overcome is the continuation of regional competition. As both East and West Berlin were heavily subsidized by their respective governments at the expense of other regions, reunification is bringing resentment of Berlin out into the open, especially in the south and west of West Germany. This is particularly dangerous because Berlin will Pes. 3 be a separate Land (state), one that is top-heavy with science. Riedmüller-Seel says she "expects a big fight" with the other Länder over aid to Berlin. The Bonn Research Ministry appears sensitive to Berlin's plight, claiming that support for Berlin is increasing.

Riedmüller-Seel realizes that it will require a clever and tenacious policy of faculty recruitment - a process that could take decades - before Berlin can raise its scientific standards. Though Väth of the Free University asserts that no professor has turned dowrt a job offer there since the opening of the Wall, he admits that there is no extra money in his budget to pursue the best researchers, especially in the natural sciences.

This is where the Max Planck Some 45 per cent of the 26,000 academy employees work in Berlin. It would not be unrealistic to estimate that half will remain after the Wissenschaftsrat recommendations are carried out, says Riedmüller-Seel. But only after the recommendations begin to emerge later this year can she incorporate in her planning the 6,000 people who are expected to remain.

After the future of the academy is settled, the next goal will be to raise the scientific quality and increase the number of students at the Humboldt University in East Berlin, which as recently as 1988 taught only 12,000 students (now 16,000) with 5,000 faculty and staff, a ratio of which West Berliners could only dream. Altogether, the universities and technical colleges of Berlin will have over 120,000 students, more than in any other city in

Although some reductions in the universities are planned due to redundancy (especially in smaller faculties such as Chinese or Japanese studies), the Free University and Humboldt University will both continue to offer courses in popular
Gesellschaft (MPG), West Germany's elite research organization, could help, says Riedmüller-Seel. MPG, which is based in Bavaria, is "fixated on southern Germany", she says, and that she will try to persuade MPG to consider placing more groups, if not entire institutes, in Berlin.

If there is to be a renaissance in Berlin, much will depend on how soon it is named the capital of Germany. Since the opening of the borders, many residents claim that the quality of life has deteriorated. Higher prices, the hordes of East German shoppers and the machinations of property agents are all causing complaint.

But once Berlin becomes the capital, there will be an influx of government agencies, foundations and even industrial lobbies that will help to invigorate the research scene, says Dietrich Mahlo, a member of the Bundestag (parliament) from West Berlin. Väth also points out that what used to be East German villages beyond the wall are now low-rent suburbs easily accessible to the Free University.

Steven Dickman 